\title{
Caregiver education in Parkinson's disease: formative evaluation of a standardized program in seven European countries
}

\author{
L. E. I. A'Campo • N. G. A. Spliethoff-Kamminga · \\ M. Macht - The EduPark Consortium - R. A. C. Roos
}

Accepted: 11 November 2009/Published online: 28 November 2009

(C) The Author(s) 2009. This article is published with open access at Springerlink.com

\begin{abstract}
Purpose The formative evaluation of a standardized psychosocial education program for patients with Parkinson's disease (PD) and their caregivers. The results of the participation of the caregivers are presented next to the data of the patients.

Methods Caregivers $(n=137)$ and patients with PD $(n=151)$ participated in the 8-week program in separate groups. Measurements were performed on psychosocial problems (BELA-P/A-k), health state (EQ-5D VAS), quality of life (PDQ-39) and depression (SDS) 1 week before and 1 week after the program. Participants rated their mood on a visual analogue scale before and after each session, and they filled in an evaluation questionnaire after the last session.

Results Scores on the BELA-P/A-k improved significantly on the 'bothered by scale' as well as the 'need for help scale'. No improvements were found on EQ-5D VAS, PDQ-39 and SDS. Mood ratings improved significantly after each session. Most participants evaluated the program as positive. Feedback led to improvements in the program, which are incorporated in a final manual.
\end{abstract}

The members of The EduPark Consortium are given in Appendix.

L. E. I. A'Campo $(\bowtie) \cdot$ N. G. A. Spliethoff-Kamminga .

R. A. C. Roos

Department of Neurology,

Leiden University Medical Center (LUMC),

Albinusdreef 2, PO Box 9600, 2300 RC Leiden,

The Netherlands

e-mail: 1.e.i.a_campo@lumc.nl

M. Macht

Institute of Psychotherapy and Medical Psychology,

University of Wuerzburg, Wuerzburg, Germany
Conclusions The program was feasible to run in the different countries. This exploratory study led to improvements in the program and recommendations for further research. A study on the effectiveness of the program is the next step.

Keywords Caregivers - Parkinson's disease · Patient education · Psychosocial · Quality of life

\begin{tabular}{|c|c|}
\hline Abbreviation & \\
\hline PD & Parkinson's Disease \\
\hline PEPP & Patient Education Program Parkinson \\
\hline MMSE & Mini Mental State Examination \\
\hline BELA-P-k & $\begin{array}{l}\text { Belastungsfragebogen Parkinson } \\
\text { kurzversion }\end{array}$ \\
\hline BELA-A-k & $\begin{array}{l}\text { Belastungsfragebogen Parkinson } \\
\text { Angehörigen kurzversion }\end{array}$ \\
\hline $\mathrm{Bb}$ & Bothered by scale \\
\hline Nfh & Need for help scale \\
\hline SDS & Self-rating Depression Scale \\
\hline EQ-5D VAS & $\begin{array}{l}\text { EuroQol Five-Dimension Visual Analogue } \\
\text { Scale }\end{array}$ \\
\hline Mood VAS & Mood Visual Analogue Scale \\
\hline PDQ-39 & Parkinson's Disease Questionnaire 39 items \\
\hline SI & Summary Index \\
\hline SPSS & Statistical Package for the Social Sciences \\
\hline
\end{tabular}

Introduction

Parkinson's disease (PD) is one of the most common neurodegenerative diseases and affects about 160 per 100,000 people (age-adjusted prevalence rate) [1] 
The emotional and practical care to most patients with PD is provided by informal caregivers, such as partners [2-4]. Caregivers often experience long-term strain across all stages of the patient's disease [5]. As a consequence, they are at risk of social isolation, losing their job, emotional burden and a reduction in quality of life [3, 4, 6-10]. Caregivers have significantly higher rates of affective (6.3 vs. $4.2 \%)$ and anxiety (17.5 vs. $10.9 \%)$ disorders than noncaregivers and use health services for mental health problems at nearly twice a rate [11]. The caregivers' well being deserves attention for several reasons. Firstly, there is a shift taking place from institutional to community care [3, 12, 13]. Moreover, caregiver burden may reduce the quality of care given to the patient and, consequently, may affect the patient's health. The caregivers' capacity to provide care determines institutional placement. Most patients prefer to live at home as long as possible [14], and for the health care budget, institutionalization is more expensive than community care $[4,9,14]$.

Although treating caregivers is recommended as an important component of a comprehensive treatment for chronic diseases [8, 12, 14-17], only few intervention studies of PD caregivers have been reported [6, 12]. The present study evaluates the Patient Education Program Parkinson (PEPP), a structured psychosocial education program for patients suffering from $\mathrm{PD}$ as well as their caregivers. The PEPP is developed by a consortium of experts with different disciplines (including neurologists and psychologists) from seven European countries (Estonia, Finland, Germany, Italy, The Netherlands, Spain and The United Kingdom) [18-23]. Also, patients with PD, caregivers and lay organizations contributed to the development. Patients and caregivers participated in a steering committee and gave their advice regarding the development of the program. The program is set up to be a systematical and professional way to support patients and their caregivers (in separate groups) by means of educating them and teaching them skills, in addition to their medical treatment, aiming to improve their quality of life. The aim was to help patients and caregivers to adapt their cognitions and behavior to the changes in their life caused by Parkinson's disease. A critical aspect of the PEPP is its personcentered approach. Patients and caregivers are viewed as experts of the disease. Participants learn that through cognitive-behavioral techniques, they can improve their own carrying capacity and interactions with the medical or social systems in which they participate. This aspect is particularly important with a chronic progressive disease such as PD, as a loss of control over their own life is what people with PD and their caregivers fear most.

The participation of the patients in the PEPP has been evaluated in the study of Macht et al. [24]. Simons et al. [25] evaluated the data from the English patients (22 patients, 14 caregivers). The aim of the present study is to present the evaluation of the participation of the caregivers from the whole sample of the seven European countries next to the results of the patients derived from the study of Macht et al. [24].

\section{Methods}

Design and procedure

All patients and caregivers attended the same treatment condition, i.e. the education program PEPP. Standardized self-report questionnaire measures were obtained 1 week before and 1 week after the program (single group pretest-post-test design). All questionnaires were filled in by the participants at the research location, in the presence of a researcher. Additionally, mood ratings were obtained before and after group sessions, and an evaluation questionnaire was given after participation. We will present the new data of the caregivers together with the key data of the patients derived from the study of Macht et al. [24].

\section{Participants}

Parkinson's disease caregivers were recruited together with the patients from local self-help groups and outpatient clinics in the seven participating European countries: Estonia $(n=18)$, Finland $(n=23)$, Germany $(n=11)$, Italy ( $n=17)$, The Netherlands $(n=16)$, Spain $(n=38)$ and The United Kingdom $(n=14)$. The patients were all diagnosed with idiopathic PD. Eligible caregivers were partners, close relatives, close friends or professional caregivers, although partners were the primary target group. The characteristics of the patients and caregivers are presented in Table 1 .

During the first assessment, patients were assigned to Hoehn \& Yahr [26] stage 1 or 2, stage 3, and stage 4 or 5, to indicate the relative disability level (stage 5 is the most disabled level). The Mini Mental State Examination (MMSE) [27] was used to indicate that none of the patients had marked cognitive impairments. Patient and caregiver characteristics were homogenous across countries. All participants gave their informed consent to participate.

\section{Intervention}

The education program had a separate but parallel program for patients and caregivers. The program consisted of eight weekly sessions of ninety minutes. Groups consisted of 4-7 participants. This relatively small group size was chosen to give all the participants the opportunity to participate actively. Trainers were professional group leaders, mostly psychologists, who were knowledgeable about patient 
Table 1 Sample characteristics of the patients and the caregivers
Abbreviations: MMSE Mini Mental State Examination, $H \& Y$ Hoehn \& Yahr

\begin{tabular}{lllll}
\hline & Patients & $n$ & Caregivers & $n$ \\
\hline Men/women & $90 / 61$ & 151 & $27 / 110$ & 137 \\
Age (years) mean (SD): & $64.4(9.2)$ & 149 & $62.2(11.3)$ & 136 \\
Relation to patient: & & & & \\
$\quad$ Partner/child/friend/sibling/professional & - & - & $119 / 9 / 4 / 2 / 2$ & 136 \\
Marital status: & & & & \\
$\quad$ Single/married/widowed/divorced & $13 / 109 / 15 / 12$ & 149 & $5 / 127 / 2 / 2$ & 136 \\
Education till age of 18/higher education & $97 / 51$ & 148 & $88 / 43$ & 131 \\
Years since diagnosis: mean (SD) & $6.5(4.3)$ & 149 & - & \\
MMSE: mean (SD) & $28.0(2.1)$ & 147 & - & \\
H \& Y stage: mean (SD) & $2.0(0.8)$ & & - & \\
$\quad$ Stage 1 and 2/Stage 3/Stage 4 and 5 & $107 / 29 / 5$ & 141 & & \\
\hline
\end{tabular}

education and the psychosocial problems of PD. Each session had its own topic (Fig. 1). The topics were mostly the same for patients and caregivers (except for session 5), but from a different perspective. During each session, the same structure was followed (Fig. 2): (1) homework discussion, (2) active information (The trainer provided information on the topic of the particular session and selfmanagement strategies and asked about the experiences of the participants with the particular subject. The patients and caregivers were motivated to participate actively), (3) exercise (practical task during the session), (4) homework for the next session and (5) appetizer (preview of the topic of the next session to enable participants to prepare themselves). The themes of the sessions overlapped: the homework assignment regarding the topic of the particular session was discussed at the beginning of the next session. Also, the appetizer returned in the active information part of the next session. Printed materials were handed out to the participants. The method used in the PEPP is based on principles of the cognitive-behavioral therapy. Interventions like systematic relaxation training, cognitive restructuring, situational behavioral analysis and training in social skills were included. The aim was to help caregivers to adapt their cognitions and behavior to the changes in their life caused by the illness of their partner.

\section{Assessment}

The impact of psychosocial problems and need for help of the patients were assessed by the 19-item Belastungsfragebogen Parkinson kurzversion (BELA-P-k) [28]. The Belastungsfragebogen Parkinson Angehörigen kurzversion (BELA-A-k) [10] is the caregiver version and contains 15 items. The questionnaire comprises four psychosocial domains (achievement capability, emotional functioning, social functioning, partner/family). Each item contains a 'bothered by' question with a Likert scale from 0 to $4 \quad(0=$ not at all, $1=$ somewhat, $2=$ moderately,
$3=$ considerably, $4=$ a great deal) and a 'need for help' question also on a Likert scale from 0 to 4 scale $(0=$ not important, 1 = hardly important, 2 = slightly important, $3=$ rather important, $4=$ very important). Total scores for the 'bothered by' and 'need for help' scale are derived by summing up the individual items of the subscales ranging from 0 to 76 in the patients and 0 to 60 in the caregivers (the higher the scores on the 'bothered by' or 'need for help' scales, the more a person is bothered by psychosocial problems or the more a person indicates that psychosocial support is important). The BELA-P/A-k has a validated version in Dutch [10, 28]. The other countries used a forward-backward translated version in their own language.

The validated visual analogue scale of the EuroQol fivedimension questionnaire (EQ-5D VAS) [29] was used to assess caregivers' present health state (from $0=$ worse imaginable health state to $100=$ best imaginable health state).

The quality of life (Qol) of the patients was assessed by the Parkinson's Disease Questionnaire (PDQ-39) [30]. The PDQ-39 contains 39 items that cover 8 dimensions (mobility, activities in daily life, emotional wellbeing, stigma, social support, cognitions, communication, physical complaints). Each item can be answered on a five-point Likert scale (from $0=$ never to $4=$ always). The Summary Index (SI) is calculated by dividing the sum of all dimensions by the number of dimensions (ranging from $0=$ best Qol to $100=$ worst Qol).

The validated Self-rating Depression Scale (SDS) [31, 32] was used to measure depression in both the patients and caregivers and consists of 10 psychological and 10 somatic symptoms. Each item is scored on a Likert scale from 1 to 4 , and a total score is derived by summing up the individual item scores (20-80 points). A score between 40 and 49 indicates a mild depression, while a score above 50 indicates a moderate to severe depression.

Patients and caregivers were asked to rate their present mood before and after each session on a visual analogue 
Fig. 1 The topics and aims of the seven sessions of the PEPP. During the program, the following questions are addressed: "Why is the particular topic important?", "How does the participant feel about the topic?", "What can the participant do?" and "How can he/she do it?". The aim of the program is to improve understanding, management and coping, with the ultimate goal to improve the quality of life of patients with PD and caregivers

\section{Session 1 \\ Information}
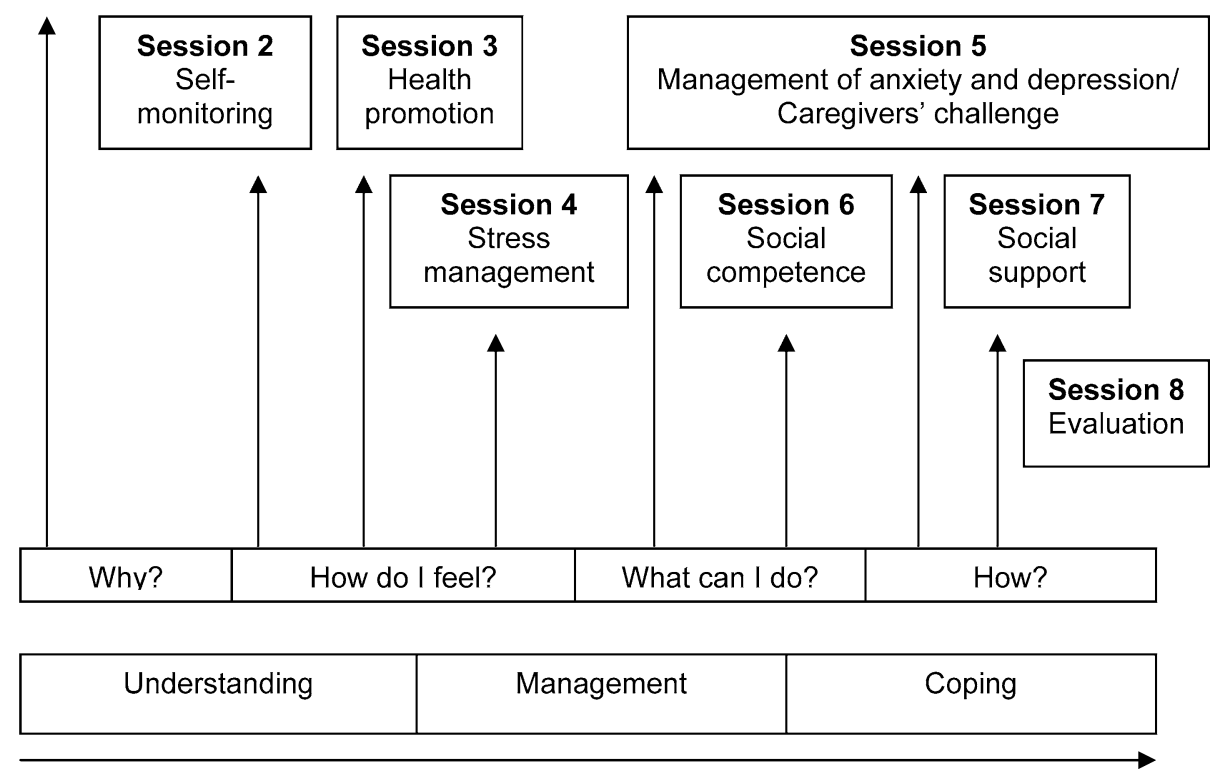

Better quality of life

Fig. 2 Structure of the sessions.

The arrows indicate the continuation of the themes in follow up sessions. The homework of the previous session is always discussed first in the next session and the appetizer returns in the active information part of the next session

\begin{tabular}{|c|c|l|}
\hline Part & 1 & Homework discussion \\
\hline Part & 2 & Active information \\
\hline Part & 3 & Exercise \\
\hline Part & 4 & Homework \\
\hline Part & 5 & Appetizer \\
\hline
\end{tabular}

\begin{tabular}{|c|c|l|}
\hline Part & 1 & Homework discussion \\
\hline Part & 2 & Active information \\
\hline Part & & Exercise \\
\hline Part & & H omework \\
\hline Part & 5 & Appetizer \\
\hline
\end{tabular}

scale (mood VAS) [33], from an extremely bad (0) to an extremely good (100) mood.

Participants were asked to evaluate the program after participation by means of an evaluation questionnaire. They could answer on a three-point scale (agree/agree somewhat/disagree). The questionnaire was adapted from a previously used evaluation tool [34].

\section{Statistical analysis}

The data were analyzed with the Statistical Package for the Social Sciences (SPSS) version 14.0. For pre-/post-session mood ratings and change in depression, psychosocial problems, health state and quality of life, paired-samples $t$-tests were used. The data from the evaluation questionnaire were analyzed descriptively, i.e. the percentages of participants who agreed with the statements in the questionnaire. The significance level used for all analyses was $P<0.05$. No adjustments were made for multiple testing, because of the exploratory approach and the correlation between the outcome measures, making a Bonferroni adjustment too conservative [35].

\section{Results}

The program was successfully applied in different settings and different cultural contexts.

The caregiver burden and need for help (BELA-A-k) diminished significantly, except for the sub score 'partner/ family bothered by' (Table 2). Health state, measured with the EQ-5D VAS, and depression, measured with the SDS, 
Table 2 Pre- and post-intervention scores of the patients and the caregivers

\begin{tabular}{|c|c|c|c|c|c|c|c|c|c|c|}
\hline \multirow[t]{2}{*}{ Scale } & \multicolumn{5}{|c|}{ Patients $^{\mathrm{a}}$} & \multicolumn{5}{|c|}{ Caregivers } \\
\hline & $n$ & Before & After & $T$ & $p$ & $n$ & Before & After & $T$ & $p$ \\
\hline \multicolumn{11}{|l|}{ BELA-P/A-k } \\
\hline Total Bb & 103 & $26.7(15.6)$ & $21.0(14.7)$ & 4.8 & $<0.001$ & 77 & $17.7(11.1)$ & $13.4(11.5)$ & 2.8 & 0.006 \\
\hline Total Nfh & 102 & $34.9(17.2)$ & $27.5(16.6)$ & 5.5 & $<0.001$ & 74 & $22.7(13.2)$ & $1.1(0.9)$ & 14.6 & $<0.001$ \\
\hline \multicolumn{11}{|c|}{ Achievement capability } \\
\hline $\mathrm{Bb}$ & 108 & $8.3(4.5)$ & $6.7(4.7)$ & 4.2 & $<0.001$ & 88 & $5.1(3.3)$ & $4.0(3.4)$ & 2.7 & 0.008 \\
\hline $\mathrm{Nfh}$ & 108 & $10.7(4.7)$ & $8.4(5.0)$ & 5.5 & $<0.001$ & 86 & $6.5(4.2)$ & $4.8(3.8)$ & 3.0 & 0.004 \\
\hline \multicolumn{11}{|c|}{ Emotional functioning } \\
\hline $\mathrm{Bb}$ & 110 & $6.7(3.9)$ & $5.0(3.5)$ & 5.3 & $<0.001$ & 94 & $6.1(3.7)$ & $4.3(3.4)$ & 3.7 & $<0.001$ \\
\hline $\mathrm{Nfh}$ & 110 & $8.5(4.4)$ & $6.4(3.9)$ & 5.2 & $<0.001$ & 91 & $7.6(4.0)$. & $5.2(3.8)$ & 4.1 & $<0.001$ \\
\hline \multicolumn{11}{|c|}{ Social functioning } \\
\hline $\mathrm{Bb}$ & 104 & $6.1(4.7)$ & $4.7(4.3)$ & 3.6 & 0.001 & 80 & $4.3(3.5)$ & $2.8(2.8)$ & 3.4 & 0.001 \\
\hline Nfh & 104 & $7.9(5.2)$ & $6.2(5.0)$ & 4.2 & $<0.001$ & 78 & $5.0(3.9)$ & $3.7(3.3)$ & 2.3 & 0.027 \\
\hline \multicolumn{11}{|l|}{ Partner/family } \\
\hline $\mathrm{Bb}$ & 90 & $5.7(5.2)$ & $4.6(4.0)$ & 2.8 & 0.006 & 67 & $3.2(2.7)$ & $2.4(2.6)$ & 1.3 & NS \\
\hline Nfh & 91 & $7.6(5.7)$ & $6.1(4.7)$ & 3.2 & 0.002 & 65 & $4.3(3.3)$ & $3.0(3.1)$ & 2.2 & 0.033 \\
\hline EQ-5D VAS ${ }^{\mathrm{b}}$ & - & - & - & - & - & 42 & $69.1(19.2)$ & $75.6(20.5)$ & -1.6 & NS \\
\hline PDQ-39 SI & 133 & $30.8(16.2)$ & 30.7 (7.7) & -0.3 & NS & - & - & - & - & \\
\hline SDS & 122 & $42.4(8.6)$ & $42.7(10.6)$ & -0.4 & NS & 118 & $39.2(9.4)$ & $38.3(8.7)$ & 0.6 & NS \\
\hline
\end{tabular}

Values are mean (SD), unless otherwise indicated. In the BELA-P/A-k, lower scores reflect less psychosocial problems or need for help. Lower scores on the EQ-5D VAS reflect worse health state. Higher scores on the PDQ-39 reflect worse quality of life. In the SDS, lower scores reflect less depressive complaints

Abbreviations: BELA-P/A-k Belastungsfragebogen Parkinson (Angehörigen) kurzversion, $B b$ Bothered by scale, $N f h$ Need for help scale, $P D Q$ 39 SI Parkinson's Disease Questionnaire-39 items Summary Index, EQ-5D EuroQol-5D, VAS visual analogue scale, SDS Self-rating Depression Scale

a Patients' data are derived from the study of Macht et al. [24], except for the 'need for help scale' data

b The EQ-5D VAS $(n=42)$ was not assessed in Spain $(n=38)$, Italy $(n=17)$, the Netherlands $(n=16)$ and Estonia $(n=18)$

showed no significant improvement after finishing the program.

As described in Macht et al. [24], patients' psychosocial burden and need for help (BELA-P-k) diminished significantly (Table 2). Quality of life measured with the PDQ-39 and depression measured with the SDS showed no significant improvement after participation in the PEPP.

The mood ratings on the VAS of the caregivers consistently improved after each session of the PEPP (Table 3). Patients' mood ratings also improved significantly $(P<0.001)$ after each session [24].

Caregivers' data from the evaluation questionnaire are presented in Fig. 3: 80\% of the caregivers fully agreed that the PEPP was appropriate to them and $86 \%$ would recommend the PEPP to other people. A high percentage (90\%) evaluated the exchange of experiences and ideas within the group as helpful. The PEPP improved understanding of PD in most of the caregivers (75\%). In $20 \%$ of the caregivers, the exercises were considered too difficult; $60 \%$ found the group leader too directive; and less than $10 \%$ experienced no active involvement.
Table 3 Pre- and post-session mood-VAS ratings of the caregivers

\begin{tabular}{lrllll}
\hline Session & \multicolumn{1}{l}{$n$} & Before session & After session & $T$ & $p$ \\
\hline 1 & 81 & $66.4(18.4)$ & $75.0(16.1)$ & -5.2 & $<0.001$ \\
2 & 118 & $67.3(20.4)$ & $73.6(20.1)$ & -5.5 & $<0.001$ \\
3 & 101 & $69.9(16.8)$ & $77.8(15.2)$ & -5.5 & $<0.001$ \\
4 & 97 & $64.3(21.8)$ & $71.4(20.6)$ & -5.6 & $<0.001$ \\
5 & 106 & $63.9(21.0)$ & $73.0(20.1)$ & -7.1 & $<0.001$ \\
6 & 107 & $68.9(15.7)$ & $76.3(14.4)$ & -6.2 & $<0.001$ \\
7 & 106 & $71.5(15.2)$ & $77.2(13.7)$ & -4.6 & $<0.001$ \\
8 & 66 & $73.1(15.0)$ & $82.9(13.5)$ & -7.1 & $<0.001$ \\
\hline
\end{tabular}

Values are mean (SD), unless otherwise indicated

The patients' evaluation [24] showed that $70 \%$ fully agreed that the intervention was appropriate to them and that the PEPP fulfilled their expectations. Many patients $(82 \%)$ reported having received helpful information in the PEPP and in 53\% understanding of PD had improved. More than half $(55 \%)$ of the patients said there was too little practice. About $75 \%$ would participate in a similar program. 
Fig. 3 Caregivers' evaluation of the program $(n=112-128)$

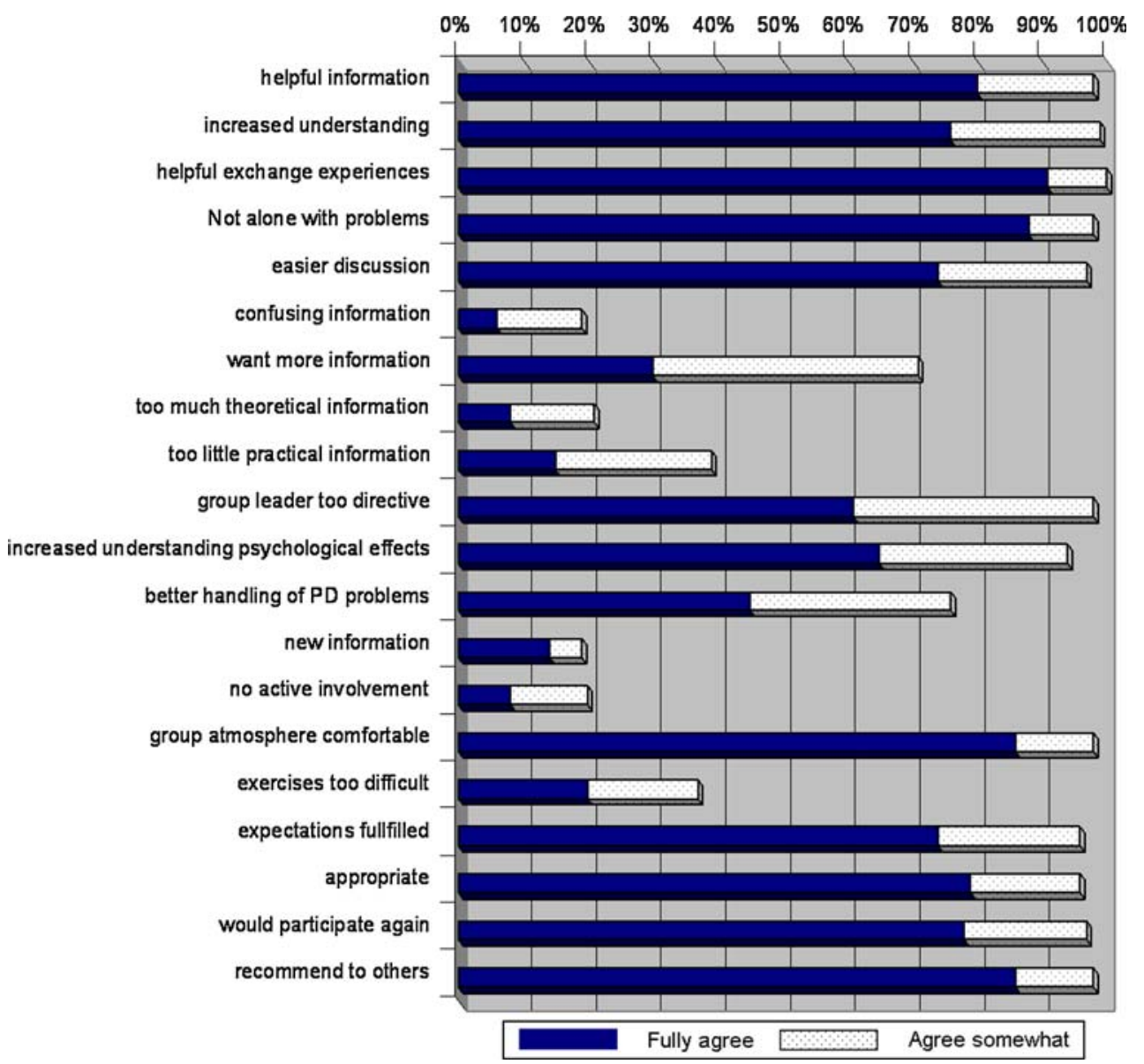

Most valued sessions by the caregivers $(n=73)$ were session 4 'Stress management' and 5 'Caregivers' challenge'. The patients $(n=110)$ valued session 4 'Stress management' and 2 'Self-evaluation' as most important. Both the patients $(n=110)$ and the caregivers $(n=62)$ evaluated session 7 'Social support' as least helpful.

The formative evaluation conclusively resulted in some adaptations to the program. The most important adaptation is that it now offers both a basic and an advanced option for exercises and homework to allow group leaders to more easily adapt to the educational and cognitive level of the group. The adaptations made because of this formative evaluation are incorporated in the final manual of the PEPP in six languages [18-23]. A description of the final content of each session can be found in Table 4 .

\section{Discussion}

The Patient Education Program Parkinson has been developed by a European consortium in order to improve the quality of life of patients with PD and caregivers. This formative evaluation has been done to evaluate the feasibility of the program and, if necessary, to make adaptations in the program, resulting in a manual in the seven participating countries (Estonia, Finland, Germany, Italy, The Netherlands, Spain and The United Kingdom). This article presents the data gathered from the caregivers in regard to their overall evaluation and the short-term benefits on psychosocial problems, depression, mood and health state received from participating in the program. We also restated the key data of the patients with $\mathrm{PD}$ from the article of Macht et al. [24] to compare the results of the patients with the results of their caregivers.

The majority of the patients and caregivers evaluated the program as positive. The PEPP appears to provide knowledge and skills essential for the self-management of PD. Especially, the exchange of information between the participants was rated to be helpful. This underlines the added value of a group format. Other advantages have been reported, such as reducing isolation and modeling one another [36]. One-fifth of the patients and caregivers evaluated the exercises, which were introduced to help them learn and develop new skills and integrate them into their daily life, as too difficult. These results correspond with the informal feedback we received from group leaders who often noted that it would have been useful to have the option of offering more basic exercises to target behavioral 
Table 4 The final thematic structure of the education program

\begin{tabular}{|c|c|c|c|}
\hline & The PEPP sessions & Structure & Main focus \\
\hline \multirow[t]{5}{*}{1} & \multirow[t]{5}{*}{ Information } & Introduction & The acquaintance and an overview of the program \\
\hline & & Active information & The importance of taking an active and central role in the health care system \\
\hline & & Exercise & How to ask questions to health care professionals \\
\hline & & Homework & To draft questions for a visit to professionals \\
\hline & & Appetizer & Past experiences with keeping a diary/journal \\
\hline \multirow[t]{6}{*}{2} & \multirow[t]{6}{*}{ Self-monitoring } & $\begin{array}{l}\text { Homework } \\
\text { discussion }\end{array}$ & Homework discussion of session 1 \\
\hline & & Active information & To learn about self-monitoring techniques, like a diary. \\
\hline & & Exercise & An exercise 'body awareness' focused on breathing and muscular tensions \\
\hline & & Homework & Option 1: Use a diary to record (i.e. fluctuations in mood or PD symptoms) \\
\hline & & & Option 2: Perform the exercise 'body awareness' \\
\hline & & Appetizer & Bring something pleasant to the next session (i.e. an object or experience) \\
\hline \multirow[t]{5}{*}{3} & \multirow[t]{5}{*}{ Health promotion } & $\begin{array}{l}\text { Homework } \\
\text { discussion }\end{array}$ & Homework discussion of session 2 \\
\hline & & Active information & To improve well being through pleasant activities \\
\hline & & Exercise & To explore pleasant activities \\
\hline & & Homework & Perform a pleasant activity every day \\
\hline & & Appetizer & Observe your own behavior in a stressful situation \\
\hline \multirow[t]{7}{*}{4} & \multirow[t]{7}{*}{ Stress management } & $\begin{array}{l}\text { Homework } \\
\text { discussion }\end{array}$ & Homework discussion of session 3 \\
\hline & & Active information & $\begin{array}{l}\text { The role of unrealistic and unhelpful thoughts in stressful situations } \\
\text { (ABC scheme) }\end{array}$ \\
\hline & & Exercise & $\begin{array}{l}\text { Option 1: Learn to replace unrealistic and unhelpful thoughts through } \\
\text { realistic helpful thoughts }\end{array}$ \\
\hline & & & Option 2: Perform relaxation exercises to deal with stress \\
\hline & & Homework & Option 1: Try alternative ways of thinking \\
\hline & & & Option 2: Relaxation training \\
\hline & & Appetizer & Observe changes of mood and causes of worry \\
\hline \multirow[t]{7}{*}{5} & \multirow{7}{*}{$\begin{array}{l}\text { Management of anxiety and } \\
\text { depression (patients)/ } \\
\text { caregiver's challenge }\end{array}$} & $\begin{array}{l}\text { Homework } \\
\text { discussion }\end{array}$ & Homework discussion of session 4 \\
\hline & & Active information & $\begin{array}{l}\text { To teach about the difference between normal feelings of anxiety and sadness } \\
\text { and when they turn into anxiety disorders or depression/caregiver overload. } \\
\text { Second, learning about the role of unrealistic, unhelpful thoughts } \\
\text { (ABC scheme) }\end{array}$ \\
\hline & & Exercise & Option 1: Usage of positive thoughts (illustrative video clip) \\
\hline & & & Option 2: Maintaining healthy activities \\
\hline & & Homework & Option 1: Think of a positive event \\
\hline & & & Option 2: Maintain healthy activities \\
\hline & & Appetizer & $\begin{array}{l}\text { Notice situations in which you want to express your thoughts and feelings but } \\
\text { not having the confidence to do so }\end{array}$ \\
\hline \multirow[t]{8}{*}{6} & \multirow[t]{8}{*}{ Social competence } & $\begin{array}{l}\text { Homework } \\
\text { discussion }\end{array}$ & Homework discussion of session 5 \\
\hline & & Active information & Social skills like communication are discussed. \\
\hline & & & Option 1: Unhelpful and helpful thoughts in communication \\
\hline & & & Option 2: Ways of communication \\
\hline & & Exercise & Discussion of a video clip addressing communication problems \\
\hline & & Homework & $\begin{array}{l}\text { Option 1: Note situations in which unhelpful thoughts contributed to a lack of } \\
\text { socially competent behavior }\end{array}$ \\
\hline & & & Option 2: Tell someone that you have PD \\
\hline & & Appetizer & To focus on the informal or formal support, you would like to receive \\
\hline
\end{tabular}


Table 4 continued

\begin{tabular}{|c|c|c|c|}
\hline & The PEPP sessions & Structure & Main focus \\
\hline \multirow[t]{5}{*}{7} & Social support & $\begin{array}{l}\text { Homework } \\
\text { discussion }\end{array}$ & Homework discussion of session 6 \\
\hline & & Active information & To discuss the importance of and how to obtain social support \\
\hline & & Exercise & Role play/discussion \\
\hline & & Homework & Finding sources of support and asking for support \\
\hline & & Appetizer & Reflecting about the entire program \\
\hline \multirow[t]{3}{*}{8} & Evaluation & $\begin{array}{l}\text { Homework } \\
\text { discussion }\end{array}$ & Homework discussion of session 7 \\
\hline & & Active information & $\begin{array}{l}\text { The group goes through the previous sessions and the program is evaluated } \\
\text { Expectations and achievements are compared }\end{array}$ \\
\hline & & Exercise & Writing a postcard for each other and filling in an evaluation questionnaire \\
\hline
\end{tabular}

The topics are the same for patients and caregivers, who participate in separate but parallel groups. Only session five has a different topic for patients (Management of anxiety and depression) and caregivers (Caregivers' challenge). Sessions have a standardized sequence: skills learned in previous sessions return in and are necessary for next sessions. The detailed description of the intervention has been written down in a manual, which is available in several languages in bookshops. Future studies are, therefore, able to replicate this intervention in several countries

change as a substitute for the more cognitively demanding exercises. In response to the feedback, an adaptation in the final program, regarding both a basic and an advanced option for exercises and homework was made. This adaptation allows group leaders to adapt the program more easily to the educational and cognitive level of the group. The final manual [18-23], with these improvements incorporated, enables professionals from different countries to replicate the intervention of this study and researchers to further investigate this particular intervention on its effectiveness.

Another result from the evaluation questionnaire was that about $60 \%$ of the participants found the group leader being too directive. This may be due to the training style of the trainers, or it may be that participants expected more a form of self-help support group in advance instead of a structured training. For professionals, it is therefore important to explain the directive style of the program at the intake meeting; being directive is sometimes necessary to provide the participants with knowledge and skills to provide more than only contact between fellow-sufferers.

After each individual session, patients and caregivers consistently reported an elevated mood when compared to their mood before the session. These mood elevations suggest a positive influence of the interventions on the participants and may be due to the specific interventions and/or to non-specific influences such as interactions between the participants.

Caregivers are less bothered by psychosocial problems due to the disease of the patient, and they have less need for help after finishing the program. The same result was found in the patients' group [24]. The program addresses psychosocial issues, like the prevention of and dealing with symptoms of depression and anxiety or caregiver burden/ overload, social competence including communication problems and addressing the importance of social support. This finding suggests that the program may be effective in teaching skills to the patients as well as the caregivers and educating them about coping with the disease and the psychosocial issues. Reductions of psychosocial problems after interventions for other chronic diseases have been reported in other studies [17].

The caregivers (and also the patients) showed no improvement in health state/quality of life and depressive symptoms after finishing the program. Quality of life was expected to improve because psychosocial functioning is a component of quality of life. In other studies regarding caregivers of different chronic diseases, improvement of health-related quality of life after participating in patient education programs has been observed $[16,17]$. It may be that our instrument (EQ-5D VAS) is not sensitive enough to detect improvements after participation in the PEPP. Or maybe the improvement of psychosocial problems was not large enough to improve the quality of life also. Because quality of life in PD decreases over time, as a result of the neurodegenerative character of PD [37], in future research, the effects on Qol should be further assessed by means of a control group. Maybe the control group would worsen in Qol, while the PEPP group would remain stable, so indicating a benefit in Qol for the patients and caregivers participating in the PEPP after all.

An absence of change in depressive symptoms seems to be due to the minimal amount of depressive complaints at baseline in most of the patients and caregivers (floor 
effect). Future research should evaluate the possible effectiveness of the PEPP in treating patients with PD and caregivers with moderate to severe depression. Despite the fact that these persons may be hard to recruit because of their depressive symptoms (i.e. reduced interest in activities, feelings of hopelessness), they may be the persons who benefit most.

Simons et al. [25] evaluated the data from the English patients and caregivers. They did not fiund any improvements on Qol, psychosocial problems and depression. Only improvements on mood were found. This lack of significant results seems to be the result of their small sample size (22 patients, 14 caregivers), because this study and the study of Macht et al. [24] did find psychosocial improvements in the complete sample (151 patients, 137 caregivers).

The present study has some methodological limitations that need to be addressed. First, no control group was included, because it was a formative first evaluation of the program. A randomized controlled trial is needed to draw further conclusions on the effectiveness of the program. Another limitation of the present study is the amount of missing values, resulting in the variety of number of cases in the data. This was mostly due to the fact that not all of the research centers assessed all of the questionnaires. Besides that, there were missing values due to participants who did not fully fill in the self-report questionnaires at pre- or post-measurements. It may be that they found the questions difficult to answer or they omitted some questions by accident. Extra check ups by the researchers directly after filling in the questionnaires by the participants are important in future research to limit the amount of missing values.

The BELA-P/A-k questionnaire was translated into the languages of the participating countries by means of a careful forward-backward method. The scale was feasible to use in the different countries. However, the scale was only validated in the Dutch language. As a consequence, the results should be interpreted with caution. In future research, the BELA-P/A-k translations should be assessed on their validity, before assessing the program on its effectiveness.

Two more recommendations for future research are (1) follow-up measurements, for example after 6 months after participation in the PEPP, in order to examine if the benefits resulting from the program continue in the near future. (2) The value of an education program like the PEPP may not be restricted to $\mathrm{PD}$, but may be adapted to other neurological disorders or to chronic diseases in general. With the worldwide increase in chronically ill patients and, with that, an increase in caregivers, interventions to improve quality of life of these people will become even more important.
In conclusion, the results of this exploratory formative evaluation indicate that the PEPP was feasible to run in different settings and different cultural contexts. Because of the limitations of this study consistent with its explorative characterization, no definite conclusions can be drawn on the program's effectiveness yet. This study led to improvements of the program incorporated in a manual and to important recommendations for future research. A study to evaluate the PEPP on its effectiveness is the next step.

Acknowledgments This research project ('Patient Education in Parkinson's Disease') was funded by the Commission of the European Union (QLK6-2002-02674 EduPark) and conducted by the European consortium EduPark formed by research centers from Germany, Spain, Finland, Italy, The Netherlands, Great Britain and Estonia. The authors thank R. Wolterbeek, Msc from the Leiden University Medical Centre for his input on the statistical analyses.

Open Access This article is distributed under the terms of the Creative Commons Attribution Noncommercial License which permits any noncommercial use, distribution, and reproduction in any medium, provided the original author(s) and source are credited.

\section{Appendix}

The other members of the EduPark Consortium:

Christian Gerlich, Heiner Ellgring, Martina Schradi; Department of Psychology, University of Wurzburg, Wurzburg, Germany.

Angels Baye's Rusinol, Maricruz Crespo, Ana Prats; Parkinson Unit, Foundation of Functional Neurosurgery, Barcelona, Spain.

Vappu Viemero, Anu Lankinen; Finnish Parkinson's Disease Association, Rehabilitation Centre Suvituuli and Department of Psycholog, Abo Akademi University, Turku, Finland.

Pionrico Ricci Bitti, Lorena Candini; Department of Psychology, University of Bologna, Bologna, Italy.

Janny de Vreugd; Department of Neurology, Leiden University Medical Center, Leiden, The Netherlands.

Gwenda Simons, Marcia Smith Pasqualini, Simon Thompson; Department of Psychology, University of Portsmouth, Portsmouth, United Kingdom.

Pille Taba, Ulle Krikmann, Eve Kanarik; Tartu Parkinson's Disease Society, Tartu, Estonia.

\section{References}

1. De Rijk, M. C., Tzourio, C., Breteler, M. M., Dartiques, J. F., Amaducci, L., Lopez-Pousa, S., et al. (1997). Prevalence of Parkinsonism and Parkinson's disease in Europe: the Europarkinson collaborative study. Journal of Neurology, Neurosurgery and Psychiatry, 62, 10-15.

2. Aarsland, D., Larsen, J. P., Karlsen, K., Lim, N. G., \& Tandberg, E. (1999). Mental symptoms in Parkinson's disease are important 
contributors to caregiver distress. International Journal of Geriatry and Psychiatry, 14, 866-874.

3. Thommessen, B., Aarsland, D., Braekhus, A., Oksengaard, A. R., Engedal, K., \& Laake, K. (2002). The psychosocial burden on spouses of the elderly with stroke, dementia and Parkinson's disease. International Journal of Geriatric Psychiatry, 17, 78-84.

4. Martinez-Martin, P., Benito-Leon, J., Alonso, F., Catalan, M. J., Pondal, M., Zamarbide, I., et al. (2005). Quality of life of caregivers in Parkinson's disease. Quality of Life Research, 14, 463472.

5. Carter, J. H., Stewart, B. J., Archbold, P. G., Inoue, I., Jaglin, J., Lannon, M., et al. (1998). Living with a person who has Parkinson's disease: the spouse's perspective by stage of disease. Movement Disorders, 13, 20-28.

6. Secker, D. L., \& Brown, R. G. (2005). Cognitive behavioural therapy (CBT) for carers of patients with Parkinson's disease: a preliminary randomised controlled trial. Journal of Neurology, Neurosurgery and Psychiatry, 76, 491-497.

7. Bhatia, S., \& Gupta, A. (2003). Impairments in activities of daily living in Parkinson's disease: implications for management. NeuroRehabilitation, 18, 209-214.

8. Oertel, W. H., \& Ellgring, H. (1995). Parkinson's disease: medical education and psychosocial aspects. Patient Eduation and Counseling, 26, 71-79.

9. Spector, J., \& Tampi, R. (2005). Caregiver depression. Annals of Long-Term Care, 13, 34-39.

10. Spliethoff-Kamminga, N. G., Zwinderman, A. H., Springer, M. P., \& Roos, R. A. (2003). A disease-specific psychosocial questionnaire for Parkinson's disease caregivers. Journal of Neurology, 250, 1162-1168.

11. Cochrane, J. J., Goering, P. N., \& Rogers, J. M. (2002). The mental health of informal caregivers in Ontario: an epidemiological survey. American Journal of Public Health, 87, 20022007.

12. Habermann, B., \& Davis, L. L. (2006). Lessons learned from a Parkinson's disease caregiver intervention pilot study. Applied Nursing Research, 19, 212-215.

13. Han, B., \& Haley, W. E. (1999). Family caregiving for patients with stroke: review and analysis. Stroke, 30, 1478-1485.

14. Mittelman, M. (2005). Taking care of the caregivers. Current Opinion in Psychiatry, 18, 633-639.

15. Acton, G. J., \& Kang, J. (2001). Interventions to reduce the burden of caregiving for an adult with dementia: a meta-analysis. Research in Nursing and Health, 24, 349-360.

16. Pinquart, M., \& Sorensen, S. (2006). Helping caregivers of persons of dementia: which interventions work and how large are their effects? International Psychogeriatrics, 11, 1-19.

17. Sorensen, S., Pinquart, M., \& Duberstein, P. (2002). How effective are interventions with caregivers? an updated metaanalysis. Gerontologist, 42, 356-372.

18. Ellgring, H., Gerlich, C., Macht, M., Schradi, M., \& EduParkKonsortium. (2006). Psycholosoziales Training bei neurologischen Erkrankungen-Schwerpunkt Parkinson. Stuttgart: W. Kohlhammer.

19. Smith Pasqualini, M. C., \& Simons, G. (2006). Patient education for people with Parkinson's disease and their carers: a manual. Chichester: Wiley.

20. Spliethoff-Kamminga, N. G. A., \& Vreugd, J. (2006). Patiënt Educatie Programma Parkinson (PEPP). Amsterdam: Harcourt Publishers.
21. Lankinen, A., Viemerö, V., Lehtonen, A., \& EduPark-projektityöryhmä. (2005). Psykososiaalinen valmennusohjelma Parkinsonin tautia sairastaville ja heidän Iäheisilleen. Turku: Suomen Parkinson-liitto ry.

22. Ricci Bitti, P. E., Candini, L., Carlini, M., Melanie, P., Razzaboni, E., \& Consorzio EduPark. (2006). Intervento psicoeducativo nella malattia di Parkinson. Gardolo: Erickson.

23. Taba, P., Kanarik, Krikmann, E., \& Ja EduPark-konsortium. (2005). Koolitusprogramm Parkinsoni tovega inimestele ja nende tugiisikutele. Tartu: Tartu Parkinsoni Haiguise Selts.

24. Macht, M., Gerlich, C., Ellgring, H., Schradi, M., Rusinol, A. B., Crespo, M., et al. (2007). Patient education in Parkinson's disease: formative evaluation of a standardized programme in seven European countries. Patient Education and Counseling, 65, 245252.

25. Simons, G., Thompson, S. B., \& Smith Pasqualini, M. C. (2006). An innovative education programme for people with Parkinson's disease and their carers. Parkinsonism and Related Disorders, 12, 478-485.

26. Hoehn, M. M., \& Yahr, M. D. (2001). Parkinsonism: onset, progression, and mortality. 1967. Neurology, 57, S11-S26.

27. Folstein, M. F., Folstein, S. E., \& McHugh, P. R. (1975). Minimental state. A practical method for grading the cognitive state of patients for the clinician. Journal of Psychiatric Research, 12, 189-198.

28. Spliethoff-Kamminga, N. G., Zwinderman, A. H., Springer, M. P., \& Roos, R. A. (2003). Psychosocial problems in Parkinson's disease: evaluation of a disease-specific questionnaire. Movement Disorders, 18, 503-509.

29. The EuroQol Group. (1990). EuroQol: a new facility for the measurement of health-related quality of life. Health Policy, 16, 199-208.

30. Peto, V., Jenkinson, C., Fitzpatrick, R., \& Greenhall, R. (1995). The development and validation of a short measure of functioning and well being for individuals with Parkinson's disease. Quality of Life Research, 4, 241-248.

31. Zung, W. W. (1965). A Self-rating Depression Scale. Archives of General Psychiatry, 12, 63-70.

32. Biggs, J. T., Wylie, L. T., \& Ziegler, V. E. (1978). Validity of the zung self-rating depression scale. British Journal of Psychiatry, 132, 381-385.33.

33. Luria, R. E. (1975). The validity and reliability of the visual analogue mood scale. Journal of Psychiatric Research, 12, 5157.

34. Macht, M., \& Ellgring, H. (2003). Psychologische Interventionen bei der Parkinson-Erkrankung: Ein Behandlungsmanual. Stuttgart: W. Kohlhammer GmbH.

35. Neuhauser, M. (2006). How to deal with multiple endpoints in clinical trials. Fundamental and Clinical Pharmacology, 20, 515523.

36. Yalom, I. (1975). Theory and practice of group psychotherapy. New York: Basic Books.

37. Visser, M., Verbaan, D., van Rooden, S., Marinus, J., van Hilten, J., \& Stiggelbout, A. (2009). A longitudinal evaluation of healthrelated quality of life of patients with Parkinson's disease. Value in Health, 12, 392-396. 